\title{
Numerical Taxonomy of Violet-Pigmented, Gram-Negative Bacteria and Description of Iodobacter fluviatile gen. nov., comb. nov.
}

\author{
NIALL A. LOGAN \\ Department of Biological Sciences, Glasgow College of Technology, Cowcaddens Road, Glasgow G4 OBA, Scotland
}

Received 17 January 1989/Accepted 31 July 1989

\begin{abstract}
A total of 113 violet chromogens, 45 of which produced spreading colonies characteristic of Chromobacterium fluviatile, were isolated from fresh water. These isolates and 27 other chromobacteria, 9 duplicates, and 11 reference strains were subjected to 95 characterization tests, and similarities were computed by using the coefficient of Gower. Cluster and principal coordinate analyses showed Janthinobacterium lividum to be a heterogeneous species but Chromobacterium violaceum and $C$. fluviatile to be well-separated and homogeneous phenons. The new, monospecific genus Iodobacter is proposed to accommodate $C$. fluviatile, which was originally placed in the genus Chromobacterium, despite its low guanine-plus-cytosine content (50 to 52 mol\%, but 65 to $68 \mathrm{~mol} \%$ for $C$. violaceum), pending the study of further isolates. The type strain of Iodobacter fluviatile comb. nov. is NCTC 11159.
\end{abstract}

Chromobacterium, a genus of violet-pigmented, gramnegative rods, was taxonomically unsatisfactory for many years, as it contained the two species $C$. violaceum, a fermentative mesophile, and $C$. lividum, a nonfermentative psychrophile. As Sneath (14) commented, "the species are almost as different from one another as are many genera". The ability of organisms to synthesize the same pigment, violacein, does not necessarily indicate a close relationship and should not be given more weight than any other taxonomic character. Indeed, the violacein-producing isolates described by Gauthier (5) had deoxyribonucleic acid (DNA) base compositions of only $41 \mathrm{~mol} \%$ guanine plus cytosine, well outside the range of 63 to $72 \mathrm{~mol} \%$ for the genus Chromobacterium. On the basis of ribosomal ribonucleic acid-DNA hybrid binding and stability studies, phenotypic data, and DNA-DNA hybridizations, De Ley et al. (4) concluded that the genus Chromobacterium should be split, and they placed the psychrophilic strains in the new genus Janthinobacterium.

Moss et al. (11) described violacein-producing isolates from river water which were fermentative and psychrophilic and which formed thin spreading colonies on low-nutrient media. These organisms shared several phenotypic properties with $C$. violaceum but formed a separate group in numerical taxonomic studies and had the much lower guanine-plus-cytosine content of 50 to $52 \mathrm{~mol} \%$, and the new species $C$. fluviatile was proposed. Subsequent ribosomal ribonucleic acid-DNA hybridization studies on the type strain of this species (9) indicated that it is taxonomically distinct from $C$. violaceum and $J$. lividum, but it was considered that $C$. fluviatile should be retained in the genus Chromobacterium until further strains had been isolated and studied, despite the discrepancy in DNA base ratios, and it appears so in the first edition of Bergey's Manual of Systematic Bacteriology (16).

The present work was undertaken to obtain further strains of $C$. fluviatile, which is infrequently isolated, to ascertain whether a new monospecific genus should be established to accommodate members of this species.

\section{MATERIALS AND METHODS}

Bacterial strains. Strains C001, C002, and C166 to C170 were $C$. violaceum NCTC $9757^{\mathrm{T}}$, F91 University of Surrey,
NCTC 9371, NCTC 9372, NCTC 9373, NCTC 9376, and NCTC 9695, respectively. Strains C003 and C004 were Janthinobacterium lividum NCTC $9796^{\mathrm{T}}$ and F1308 University of Surrey, respectively. Strains $\mathrm{C} 005$ to $\mathrm{C} 010$ were $C$. fluviatile 162 (14), NCTC 11160, 163, 164, NCTC 11159' , and NCTC 11161, respectively. Other reference strains were AM01 (Aeromonas hydrophila NCIB 9240), AM02 (Aeromonas salmonicida NCTC 10402), AS01 (Alcaligenes faecalis NCIB 8156), BA01 (Bordetella bronchiseptica NCTC 452), PL01 (Plesiomonas shigelloides NCIB 9242 ${ }^{\mathrm{T}}$ ), PS01 (Pseudomonas solanacearum NCPPB 325), PS02 (Pseudomonas acidovorans NCIB 9681 ${ }^{\mathrm{T}}$ ), PS03 (Pseudomonas cepacia NCIB 8507), PS04 (Pseudomonas testosteroni NCIB 8955 ${ }^{\mathrm{T}}$ ), PS05 (Pseudomonas aeruginosa NCTC 10332 ${ }^{\mathrm{T}}$ ), and VO01 (Vibrio parahaemolyticus NCMB 1164). Janthinobacterium strains $\mathrm{C} 067, \mathrm{C} 070$, and $\mathrm{C} 071$ were Antarctic soil core isolates B232.2 (Signy Island, South Orkney Islands) and MP5.5 and MP1.1 (Maiviken, South Georgia) (supplied by D. D. Wynn-Williams, British Antarctic Survey); C072 to $\mathrm{C} 075$ and $\mathrm{C} 077$ to $\mathrm{C} 079$ were soil isolates (C. Ryall strains, supplied by M. O. Moss, University of Surrey, Guildford, United Kingdom) 77A, 108, 130, 136, 145, 152, and 153; C057 and $\mathrm{C} 060$ were isolated from violet-pigmented composting eggshells. All other strains were isolated in Scotland from fresh water. C011 to C028, C030 to C044, C046, C048, C050, $\mathrm{C} 053, \mathrm{C} 054, \mathrm{C} 058, \mathrm{C} 061$ to $\mathrm{C} 063, \mathrm{C} 081, \mathrm{C} 085$ to $\mathrm{C} 087, \mathrm{C} 093$ to $\mathrm{C} 095, \mathrm{C} 097, \mathrm{C} 098, \mathrm{C} 100, \mathrm{C} 102, \mathrm{C} 107$ to $\mathrm{C} 113, \mathrm{C} 117$ to $\mathrm{C} 120, \mathrm{C} 124, \mathrm{C} 126, \mathrm{C} 127, \mathrm{C} 130, \mathrm{C} 131, \mathrm{C} 134, \mathrm{C} 135, \mathrm{C} 137$ to $\mathrm{C} 139, \mathrm{C} 152$ to $\mathrm{C} 165, \mathrm{SUC1}$, and SUC3 were isolated from lowland burns in Baldernock, Stirlingshire, United Kingdom. C089 was isolated from Garb Uisge, Kilmahog, Stirlingshire. C142, C143, C147, C148, C150, and C151 were isolated from River Carron, Stirlingshire. C180 to C184 were isolated from Malls Myre, Glasgow (supplied by D. Cullen, Glasgow College of Technology). C185 to C194 were isolated from Clatteringshaws Loch (mean $\mathrm{pH}, 4.1$ ), Kirkudbrightshire, United Kingdom. C195 was isolated from West Burn, Glasgow (supplied by D. Cullen).

Isolation and maintenance of strains. Strains of Chromobacterium and Janthinobacterium species were isolated by spreading 0.5 - or $0.1-\mathrm{ml}$ quantities of undiluted water samples on 14- or 9-cm plates containing the medium described by Ryall and Moss (12): Nutrient Broth no. 1 (Oxoid Ltd. 
Basingstoke, Hampshire, United Kingdom) at one-quarter strength (1-NB) solidified with $1.2 \%$ agar (Oxoid) (1- Nutrient Agar [ $\left.\left.{ }^{1} \mathrm{NA}^{4}\right]\right)$ and supplemented with filter-sterilized solutions of colistin sulfate (Colomycin; Pharmax Ltd. Bexley, Kent, United Kingdom), cycloheximide, and sodium deoxycholate to give final concentrations of 15,30 , and $300 \mu \mathrm{g} / \mathrm{ml}$, respectively. The medium described by Keeble and Cross (7) was also used initially but was found to be unsuitable for the isolation of $C$. fluviatile, which only grew from heavy inocula, forming plicated, nonspreading colonies. Plates were incubated at $25^{\circ} \mathrm{C}$ for 5 to 7 days, and violet colonies, especially those with spreading morphologies, were picked off, streaked on $1 \mathrm{NA}$, and incubated at $25^{\circ} \mathrm{C}$ for 4 days to check purity. Strains SUC1, SUC3, C124, C126, C127, $\mathrm{C} 130, \mathrm{C} 131$, and $\mathrm{C} 134$ were unpigmented isolates recognized on the basis of colonial morphology and confirmed as Chromobacterium or Janthinobacterium species by flagellum staining and a limited number of biochemical tests. Pure cultures were transferred to $-\mathrm{NB}$, incubated at $25^{\circ} \mathrm{C}$ for 2 days, and then stored at $4^{\circ} \mathrm{C}$. All strains were lyophilized in $5 \%$ meso-inositol nutrient broth.

Characterization tests and scoring of results. All media were inoculated with one drop of $1 \mathrm{NB}$ culture grown overnight at $25^{\circ} \mathrm{C}$ and, with the exception of those used for growth temperature tests, were incubated at $25^{\circ} \mathrm{C}$. Media for strain VO01 were supplemented with $1 \% \mathrm{NaCl}$ when necessary for growth. Results were scored in binary form $(0$, negative; 1 , positive) or quantitatively $(0$, negative; 1 , doubtful; 2 , trace reaction; 3 , weak positive; 4 , moderate positive; 5 , strong positive; or radii of inhibition zones in antibiotic sensitivity tests), the method used being indicated below after each test series.

Test control and reproducibility. Reference strains acted as positive and negative controls for most tests; other bacteria known to give either positive or negative reactions were included in the remaining tests to aid interpretation. Nine strains (C035, C058, C085, C102, C107, C118, C119, C185, and C193) were chosen at random and carried through in duplicate to ascertain test reproducibility.

Colonial morphology and pigmentation. Bacteria were grown on 1 NA for 5 days and observed for concentric zoning of pigment (unpigmented strains were scored as no comparison); butyrous, gelatinous, tough, and membranous colonial textures; and spreading or plicated colonies (scored as 0 or 1). Bacteria were also grown on glucose yeast extract agar (containing [in grams per liter]: peptone, 2.5; $\mathrm{NaCl}, 2.5$; yeast extract, 2.5; glucose, 5; agar, 12) adjusted to $\mathrm{pH} 7.0$ and autoclaved at $115^{\circ} \mathrm{C}$ for $20 \mathrm{~min}$ for observation of violacein production (scored from 0 to 5), the identity of the pigment being confirmed by the nonspectrophotometric tests of Sneath (16), and for other pigments (scored as 0 or 1).

Microscopy. Overnight cultures in 1 NB were examined by phase-contrast microscopy for straight rods, curved rods, rounded ends, pointed ends, and chains of more than two cells and were examined after 2 days for filament formation (scored as 0 or 1 ). Overnight cultures on slopes of 1 NA were flagellum stained by using the method of Mayfield atnd Inniss (8) (with the proportion of alcoholic basic fuchsin in the mordanting solution raised from 0.8 to 0.95 ) and examined for lateral and polar flagella (scored as 0 or 1 ).

Growth tests. Abilities of strains to grow in $1 \mathrm{NB}$ at 4,30 , and $37^{\circ} \mathrm{C}$ were tested after 7,4 , and 2 days, respectively. Growth in $1 \mathrm{NB}$ with $1,2,4$, and $6 \% \mathrm{NaCl}$, in $1 \mathrm{NB}$ at $\mathrm{pH} 3,4$, 5 , and 6 , ơ nutrient agar containing four times the usual concentration of Nutrient Broth (Oxoid) (4NA), on minimal medium (2) (scored as 0 or 1), and anaerobically on Nutrient Agar (Oxoid) in a GasPak jar (BBL Microbiology Systems, Baltimore, Md.) (scored as 0 to 5) were tested after 7 days.

Biochemical tests. The oxidase test was performed by the method of Sivendra et al. (13) (scored as 0 or 1). Oxidation (scored as 0 to 5) and fermentation (scored as 0 to 5) of glucose and gas production from glucose (scored as 0 or 1 ) were tested in the glucose- $\mathrm{H}_{2} \mathrm{~S}$ medium of Ward et al. (18), which was examined daily for 5 days. Acid production from $N$-acetylglucosamine, L-arabinose, D-cellobiose, D-fructose, D-galactose, gluconate, D-glucose, glycerol, glycogen, mesoinositol, inulin, lactose, D-maltose, D-mannitol, D-mannose, melezitose, D-raffinose, D-sorbitol, starch, sucrose, trehalose, or D-xylose was indicated by a yellow reaction in a deep-butted slope of medium containing the following substances (in grams per liter): $\left(\mathrm{NH}_{4}\right)_{2} \mathrm{PO}_{4}, 1 ; \mathrm{KCl}, 0.2$; $\mathrm{MgSO}_{4} \cdot 7 \mathrm{H}_{2} \mathrm{O}, 0.2$; yeast extract, 0.2 ; agar, 12 ; and phenol red, 0.06. The medium was adjusted to a $\mathrm{pH}$ of 7.4 and autoclaved at $121^{\circ} \mathrm{C}$ for $15 \mathrm{~min}$, and filter-sterilized carbohydrate solution was added to give a final concentration of $0.5 \%$. Tubes were examined at 2,4 , and 7 days (scored as 0 to 5). Utilization of acetate, citrate, fumarate, glycerate, lactate, malate, proprionate, pyruvate, succinate, or tartrate as the sole carbon source was tested in the medium of Gordon and Mihm (6) modified by increasing the concentration of phenol red to $0.06 \mathrm{~g} /$ liter; slopes were examined for red reactions at 2, 4, and 7 days (scored as 0 to 5). Hydrolysis of aesculin, arginine, and casein, the egg yolk reaction, and production of $\mathrm{HCN}$ were tested by the methods of Sneath (16) (scored as 0 to 5). Hemolysis on $5 \%$ horse blood in Columbia Blood Agar base (Oxoid) was examined after 2 days (scored as 0 to 5). Hydrolysis of gelatin and starch in nutrient agar plates were tested by the methods of Cowan and Steel (1) at 7 days (scored as 0 to 5). Nitrate reduction, destruction of nitrite, and gas production from nitrite were tested in nitrate broth (1) at 7 days using Merckoquant nitrate test strips (Merck, Darmstadt, Federal Republic of Germany).

Antibiotic sensitivities. Multodises U2 and 30-12L (Oxoid) containing ampicillin $(25 \mu \mathrm{g})$, cephaloridine $(25 \mu \mathrm{g})$, colistin sulfate $(10 \mu \mathrm{g})$, kanamycin $(30 \mu \mathrm{g})$, nalidixic acid $(30 \mu \mathrm{g})$, nitrofurantoin $(200 \mu \mathrm{g})$, sulfafurazole $(500 \mu \mathrm{g})$, tetracycline $(50 \mu \mathrm{g})$, chloramphenicol $(10 \mu \mathrm{g})$, chlortetracycline $(10 \mu \mathrm{g})$, furazolidone $(50 \mu \mathrm{g})$, neomycin $(10 \mu \mathrm{g})$, oxytetracycline $(10$ $\mu \mathrm{g})$, streptomycin $(10 \mu \mathrm{g})$, sulfafurazole $(100 \mu \mathrm{g})$, and penicillin G (1.5 IU) were placed on - NA lawn plates, and radii of zones of complete inhibition were measured (in millimeters) from the edges of the disks after 2 days (scored as 0 to 18). Sensitivity to filter paper disks containing $50 \mu \mathrm{g}$ of vibriostatic agent $0 / 129$ (2,4-diamino-6,7-diisopropylpteridine; Sigma Ltd., Poole, Dorset, United Kingdom) was determined on 1 NA streak plates after 2 days (scored as 0 or 1 ).

Analysis of results. Similarities were calculated by using the general similarity coefficient, $\left(S_{\mathrm{G}}\right)$ of Gower, clusters formed by the unweighted pair group method using arithmetic averages, and principal coordinates computed by using the GENSTAT IV package on the Prime 9955 computer at the Glasgow College of Technology. Ordination plots were rotated by using the MACSPIN program $\left(D^{2}\right.$ Software Inc., Austin, Texas) on an Apple Macintosh microcomputer.

\section{RESULTS}

The nine duplicates and their homologous strains showed similarities ranging from 98.9 to $89.5 \% S$, with a mean of $95.5 \% S$. This implies an overall test error of $4.5 \%(P$ $\sim 2.25 \%$ ), which is acceptably low (17), especially since many of the data were scored quantitatively.

Rotated principal coordinates plots of vectors 1, 2, and 3, which together accounted for $63 \%$ of the variation in the data (vector $1,36 \%$; vector $2,17 \%$; vector $3,10 \%$ ), for 70 
(a)

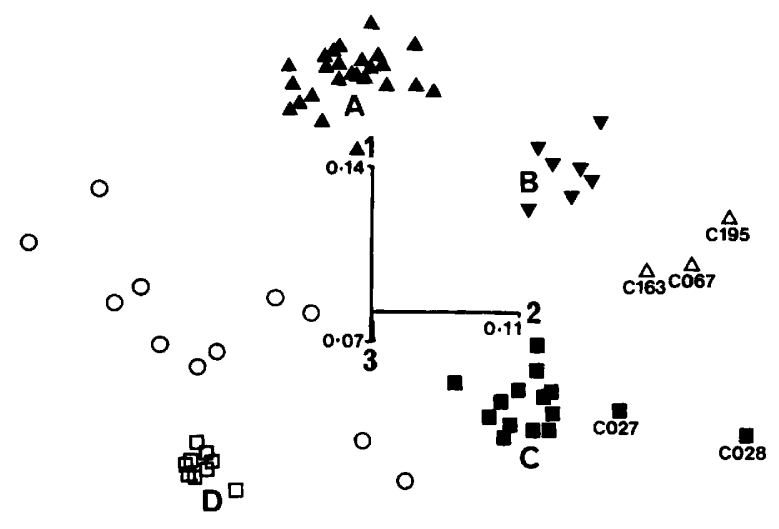

(b)

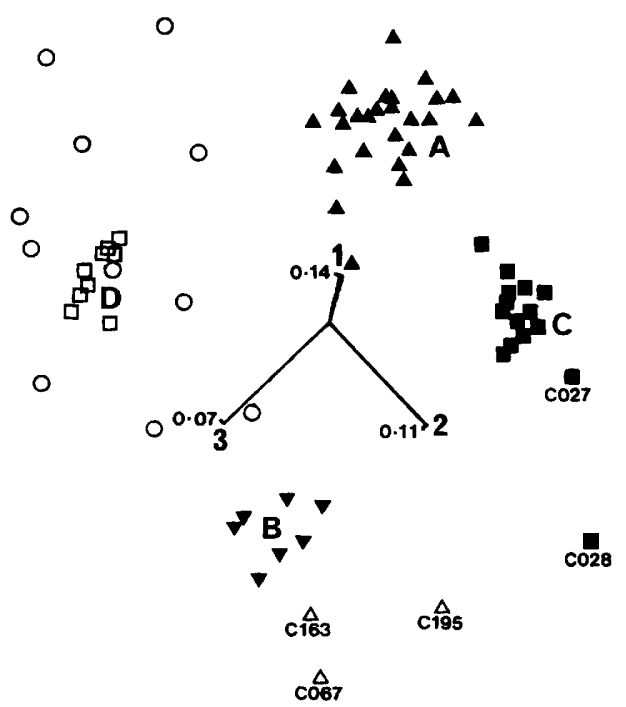

FIG. 1. Rotated principal coordinate plots of the first three vectors of an analysis of 70 representative strains. $\mathbf{0}$, fluviatile; $\square, C$. violaceum; $\boldsymbol{\Delta}, \boldsymbol{\nabla}$, and $\triangle$, Janthinobacterium lividum; $O$, reference strains. Groups A through D are indicated. Panel b is a rotated view of panel a so that it is viewed from above.

representative strains are shown in Fig. 1. The computer program had a capacity of 70 strains, but different sets of strains gave similar results. Four main groups (A, B, C, and D) which remained stable when rotated may be recognized. In Fig. 1a, the reference strains lie in a diffuse band between group D and the other groups, and five strains of chromobacteria (C027, C028, C067, C163, and C195) lie at some distance from any other group. In Fig. 1b, the plot shown in Fig. 1a has been rotated so that it is viewed obliquely from above.

The phenogram (Fig. 2) shows that four clusters formed at the $56 \% S$ level, leaving one strain unattached. Cluster 1 contained all but three of the strains, including unpigmented ones, tentatively identified as $J$. lividum on isolation, and the type strain of the species. Seven smaller clusters (1.1 to 1.7) forming at between 70 and $80 \% S$ have been indicated to facilitate discussion; clusters 1.1 to 1.5 and the ungrouped strains C085 to C147 correspond to group A in the principal coordinate plots.

Cluster 1.1 contained the type strain of $J$. lividum the one other culture collection strain of this species, and six strains (C011, C012, C050, C058, C117, and C139) isolated from water; members of the group shared no distinctive property. The 15 strains (C135, C137, C138, C143, C148, C150, C154, $\mathrm{C} 155, \mathrm{C} 157-\mathrm{C} 159, \mathrm{C} 161, \mathrm{C} 164, \mathrm{C} 165$, and $\mathrm{C} 186$ ) in cluster 1.2 were isolated from water, one of them from the acidified Clatteringshaws Loch, and the majority formed butyrous colonies with zoning of pigment. Cluster 1.3 contained the 19 isolates $\mathrm{C} 044, \mathrm{C} 073, \mathrm{C} 077, \mathrm{C} 079, \mathrm{C} 097, \mathrm{C} 142, \mathrm{C} 151$ to $\mathrm{C} 153$, C156, C160, C162, C180 to C184, SUC1, and SUC3 isolated from soil and water, all of which produced membranous colonies most of which became plicated with age; SUC1 and SUC3 were unpigmented isolates suspected to be J. lividum on the basis of their plicated, membranous colonies. Cluster 1.4 contained the 18 strains C013, C043, C048, C057, C060, C074, C075, C078, C086, C087, C095, C107, C108, C124, $\mathrm{C} 126, \mathrm{C} 127, \mathrm{C} 131$, and $\mathrm{C} 134$ isolated from soil, water, and egg shell membranes, and although members shared no distinctive character (as with cluster 1.1), one-third were unpigmented isolates. Cluster 1.5 comprised the three soil isolates $\mathrm{C} 070$ to $\mathrm{C} 072$, two of which came from South Georgia, and all produced gelatinous colonies. Strains C085 and $\mathrm{C} 147$ were isolated from water and produced tough, gelatinous colonies.

Clusters 1.6 and 1.7 correspond to group B in the ordination plots. The five members (C089, C093, C094, C098, and $\mathrm{C} 100)$ of cluster 1.6 were water isolates which mainly produced gelatinous colonies which were tough and plicated in several strains. Cluster 1.7 contained isolates C187 to C194 from the acidified Clatteringshaws Loch; all produced tough, plicated, gelatinous colonies and shared with members of cluster 1.6 the distinctive properties of producing acid from glycogen and trehalose and failing to produce acid from polyalcohols (glycerol, inositol, mannitol, and sorbitol) or to hydrolyze aesculin. Results for several other tests such as hemolysis and growth in $1 \% \mathrm{NaCl}$ and on minimal medium were usually negative for group $B$ strains but were positive for group A. Members of these two clusters were not separated in the ordination plots. Strains C067, C163, and C195 were recognizable as $\boldsymbol{J}$. lividum, but all grew poorly and produced weak acid reactions from few carbohydrates.

Cluster 2.1 contained 45 typical strains ( $\mathrm{C} 005$ to $\mathrm{C} 010$, $\mathrm{C} 014$ to $\mathrm{C} 026, \mathrm{C} 030$ to $\mathrm{C} 042, \mathrm{C} 046, \mathrm{C} 053, \mathrm{C} 054, \mathrm{C} 061$ to C063, C081, C102, C111 to C113, C120, and C130) of $C$. fluviatile, including the type strain, all of which produced spreading, butyrous colonies; all but two strains clustered above $80 \% \mathrm{~S}$. The four strains C109, C110, C118, and C199 in cluster 2.2 formed only slightly spreading colonies (scored as nonspreading), and for two of them (C109 and C110) these were slightly gelatinous; a notable character of members of this cluster was a positive egg yolk reaction. Clusters 2.1 and 2.2 are not separated in the ordination plots, where they form group $\mathrm{C}$. The two ungrouped strains $(\mathrm{C} 027$ and $\mathrm{C} 028)$ formed discrete nonspreading colonies and were tentatively identified as J. lividum on isolation; $\mathrm{C} 027$ was unpigmented, and $\mathrm{C} 028$ fermented fewer carbohydrates, utilized fewer organic acids, and showed greater sensitivity to several antibiotics than did other strains of $C$. fluviatile, and it lies at some considerable distance from other members of this taxon in the ordination plots. In the cluster analysis, members of $C$. fluviatile merged by $68 \% S$, with all but the two strains $\mathrm{C} 027$ and $\mathrm{C} 028$ merging by $79 \% S$; this phenon joined 


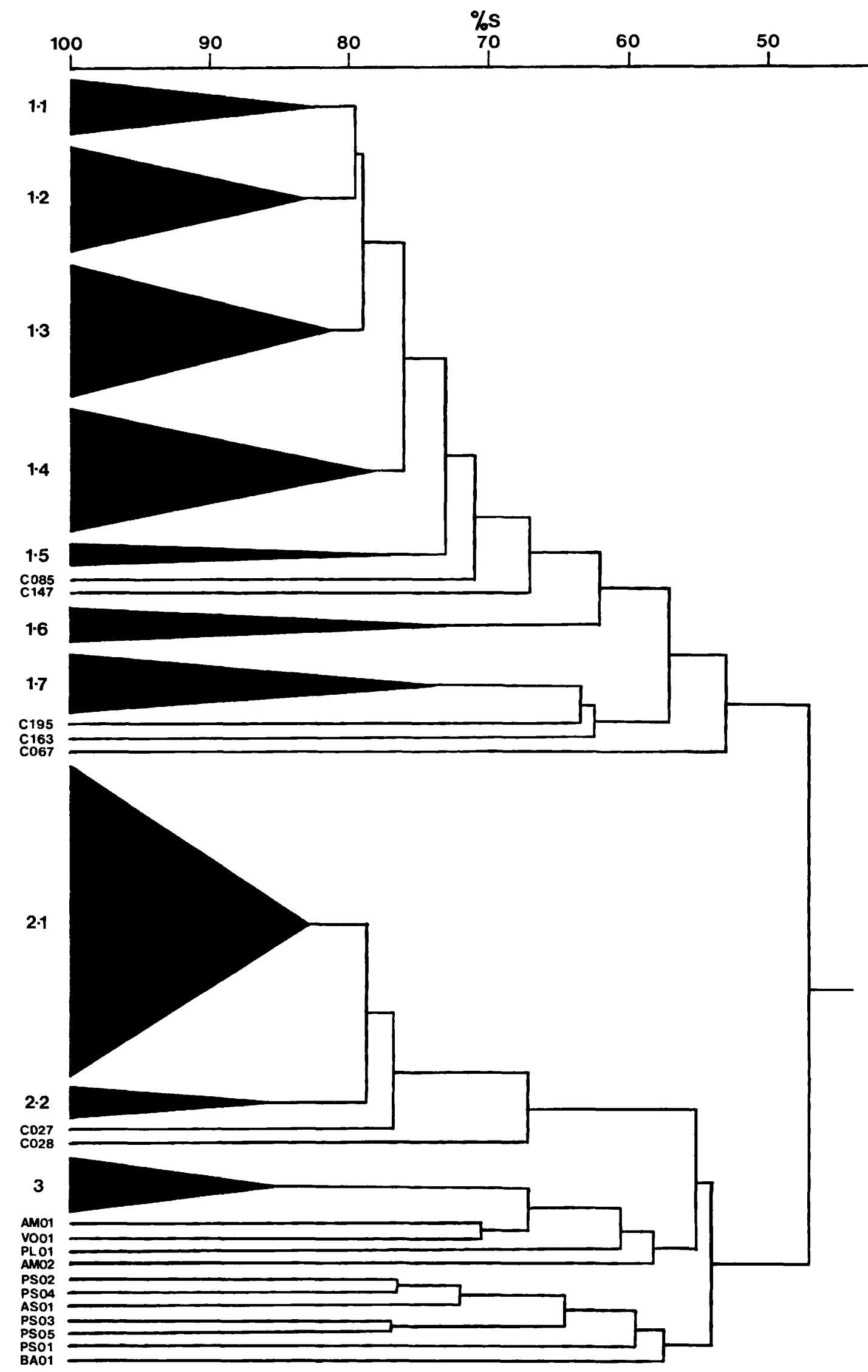

FIG. 2. Phenogram based on unweighted pair group method using arithmetic averages analysis of 140 chromobacteria and 11 reference strains. Clusters 1.1 to 1.5 and strains C085 and C147, J. lividum; 1.6, 1.7, and strains C195, C163, and C067, atypical strains of J. lividum; 2.1, 2.2, and strains C027 and C028, C. fluviatile; 3, C. violaceum; AM01, Aeromonas hydrophila; VO01, Vibrio parahaemolyticus; PL01, Plesiomonas shigelloides; AM02, Aeromonas salmonicida; PS02, Pseudomonas acidovorans; PS04, Pseudomonas testosteroni; AS01, Alcaligenes faecalis; PS03, Pseudomonas cepacia; PS05, Pseudomonas aeruginosa; PS01, Pseudomonas solanacearum; and BA01, Bordetella bronchiseptica. 
TABLE 1. Patterns of results in diagnostically useful tests

\begin{tabular}{|c|c|c|c|c|c|c|c|c|c|}
\hline \multirow[t]{2}{*}{ Property } & \multicolumn{4}{|c|}{$\begin{array}{c}\% \text { Positive } \\
\text { in group } \\
\text { (no. of strains): }\end{array}$} & \multicolumn{5}{|c|}{$\begin{array}{c}\text { Results for } \\
\text { ungrouped strain: }\end{array}$} \\
\hline & $\begin{array}{c}\mathrm{A} \\
(68)\end{array}$ & $\begin{array}{c}\text { B } \\
(14)\end{array}$ & $\underset{(53)}{C}$ & $\begin{array}{l}\mathrm{D} \\
(9)\end{array}$ & $\mathrm{C} 063$ & C167 & C195 & $\mathrm{C} 027$ & $\mathrm{C} 028$ \\
\hline Spreading colonies & 0 & 0 & 89 & 0 & - & - & - & - & 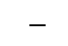 \\
\hline Gelatinous colon & 38 & 100 & 4 & 0 & + & + & + & & - \\
\hline Tough colonies & 7 & 71 & 0 & 0 & - & + & + & - & - \\
\hline Growth at $4^{\circ} \mathrm{C}$ & 97 & 93 & 100 & 0 & - & + & + & + & + \\
\hline Growth at $37^{\circ} \mathrm{C}$ & 0 & 0 & 0 & 100 & - & - & - & - & - \\
\hline $\begin{array}{l}\text { Growth on minimal } \\
\text { medium }\end{array}$ & 100 & 7 & 96 & 100 & - & - & - & - & - \\
\hline Anaerobic growth & 3 & 0 & 100 & 100 & - & - & - & - & - \\
\hline Gl & $\mathbf{0}$ & 0 & 100 & 100 & - & - & - & + & + \\
\hline Glucose oxidiz & 97 & 57 & 0 & 0 & - & - & + & - & - \\
\hline \multicolumn{10}{|l|}{ Acid from: } \\
\hline L-Arabinose & 100 & 100 & 0 & 0 & - & - & - & - & - \\
\hline D & 97 & 100 & 0 & 0 & + & - & + & - & - \\
\hline Gala & 100 & 93 & 0 & 0 & + & + & - & - & - \\
\hline Gluco & 1 & $\mathbf{0}$ & 96 & 100 & - & - & - & + & + \\
\hline Glycerol & 98 & $\mathbf{0}$ & 13 & 100 & - & - & + & - & - \\
\hline Glycogen & 3 & 100 & 0 & 89 & - & - & - & - & - \\
\hline meso-Inositol & 100 & 0 & 0 & $\mathbf{0}$ & - & - & - & - & - \\
\hline Malt & 98 & 93 & 100 & 0 & + & + & + & + & + \\
\hline D-Mannitol & 97 & 0 & $\mathbf{0}$ & $\mathbf{0}$ & - & - & - & - & - \\
\hline $\begin{array}{l}\text { N-Acetylgluco- } \\
\text { samine }\end{array}$ & 1 & 0 & 100 & 100 & - & - & - & + & + \\
\hline Trehalose & 1 & 100 & 100 & 100 & + & - & + & + & + \\
\hline & 100 & 93 & 0 & 100 & - & + & - & - & - \\
\hline Aesculin hydrolysis & 100 & 0 & $\mathbf{0}$ & 0 & - & - & - & - & - \\
\hline Arginine hydrolysis & $\mathbf{0}$ & 0 & $\mathbf{0}$ & 100 & - & - & - & - & - \\
\hline HCN production & $\mathbf{0}$ & 0 & $\mathbf{0}$ & 100 & - & - & - & - & - \\
\hline
\end{tabular}

${ }^{a}$ Groups: A, J. lividum; B, atypical J. lividum; C, I. fluviatile; D, C violaceum. Groups were indicated by principal coordinate analysis.

the cluster containing $C$. violaceum at $55 \%$, and both groups were well separated in the ordination plots, with strains of $C$. violaceum forming group $\mathrm{D}$.

Cluster 3 contained eight strains of $C$. violaceum, $\mathrm{C} 001$, $\mathrm{C} 002, \mathrm{C} 166$ to $\mathrm{C} 170$, and $\mathrm{C} 185$, the last of these being a fresh isolate from Clatteringshaws Loch; all clustered above $85 \%$ $S$ and formed a tight phenon. The reference strains of $A$. hydrophila and $V$. parahaemolyticus merged with $C$. violaceum at $67 \% \mathrm{~S}$, with Plesiomonas shigelloides at $60.5 \% \mathrm{~S}$, and with $A$. salmonicida at $58 \% S$. Thus, the $C$. violaceum phenon showed greater similarity to these reference strains than it did to $C$. fluviatile.

Table 1 shows the patterns of results for the groups A, B, $C$, and $D$ and the five ungrouped strains in the diagnostically useful tests; only results scored as 3 or higher in the quantitative tests were counted as positive.

The antibiotic sensitivity patterns and mean zone sizes were largely similar between the groups; the majority of strains were sensitive to chlortetracycline, kanamycin, nalidixic acid, and tetracycline, moderately sensitive to oxytetracycline, slightly sensitive to neomycin, streptomycin and sulfafurazole, and resistant to ampicillin, cephaloridine, colistin, penicillin $\mathrm{G}$, and vibriostatic agent $0 / 129$. The most noticeable differences were the resistance of $J$. lividum strains and the sensitivities of $C$. violaceum and $C$. fluviatile strains to nitrofurantoin and the greater sensitivities of $C$. fluviatile to chloramphenicol and of $C$. violaceum and $C$. fluviatile to furazolidone. The slight sensitivity of most strains to neomycin explains the unsuitability of the medium of Keeble and Cross (7) for isolating certain types of $J$. lividum (19) and C. fluviatile.

\section{DISCUSSION}

Clusters 1.1 to 1.5 , which merged between 70 and $80 \% S$, may be regarded as a homogeneous group of typical $J$. lividum strains, with clusters 1.6 and 1.7 representing atypical strains corresponding to the former species " $C$. amethystinum" and "C. membranaceum". Moss and Ryall (10) found atypical strains of $J$. lividum to be more frequently isolated from soil, and so it is of particular interest that the proportions of typical and atypical strains are the same (84 and $16 \%$, respectively) in the study of Moss et al. (11) and in the present work despite the different sources of the strains (discounting those from culture collections): $60 \%$ were from water, $24 \%$ were from riparian soils, and $16 \%$ were from river sediments in the earlier study, and $86 \%$ were from water and $14 \%$ were from soil in the present one.

The genus Janthinobacterium falls into two main groups in the principal coordinates analysis, but the picture is less distinct in the phenogram in which cluster 1.6 merges with clusters 1.1 to 1.5 , which contain typical strains, at a higher $S$ than that of its merger with cluster 1.7. Sneath (15) found that gelatinous (atypical) strains and other strains of $J$. lividum cross-reacted serologically and did not differ notably in other ways. The ribosomal ribonucleic acid-DNA hybridization studies of De Ley et al. (4) indicated one slightly elongated group rather than two groups, but it is unclear whether their collection of 11 cultures included strains which were truly atypical in the present sense. J. lividum must therefore continue to be regarded as a heterogeneous species.

The homogeneity of $C$. violaceum and the stabilities of its members are emphasized by the high similarities of the fresh isolate C185 to the "museum piece" strains from culture collections. Being a mesophilic saprophyte, $C$. violaceum is particularly associated with tropical environments, as are its opportunistic infections, called chromobacteriosis, of man and other mammals (review manuscript in preparation), but strains have been found in cooler habitats. Strain C185 came from acidified loch water which has a mean temperature of perhaps $9^{\circ} \mathrm{C}$ (range, 3 to $18^{\circ} \mathrm{C}$ ), and isolates from Antarctic lakes and soils, some of which were acidic, have been reported (19). It is noteworthy, therefore, that all of the $C$. violaceum strains in this study grew in ${ }^{1} \mathrm{NB}$ at $\mathrm{pH} 4$, whereas the majority of strains of the other two species, including most of those of $J$. lividum from Clatteringshaws Loch (mean $\mathrm{pH}, 4.1$ ), did not. Sneath reported no growth of Chromobacterium or Janthinobacterium species below pH 5 $(15,16)$, but Wynn-Williams (19) isolated acid-tolerant strains of $J$. lividum in the Antarctic and considered the $\mathrm{pH}$ range for polar habitats of this species to be from 3.5 to 9.0 .

Most of the strains of $C$. fluviatile form a homogeneous group in cluster analysis and in principal coordinates analysis, and the two outlying or atypical strains, $\mathrm{C} 027$ and $\mathrm{C} 028$, are recognizably members of this species, which is well separated from Janthinobacterium species, C. violaceum, and the reference strains. Indeed, $C$. violaceum strains show greater similarity to reference strains of the family Vibrionaceae and members of rRNA superfamily I of De Ley (3) than they do to $C$. fluviatile or to members, such as Alcaligenes faecalis, $B$. bronchiseptica, Janthinobacterium species, $\boldsymbol{P}$. acidovorans, $\boldsymbol{P}$. cepacia, $\boldsymbol{P}$. solanacearum, and $\boldsymbol{P}$. testosteroni, of rRNA superfamily III, to which they belong.

C. fuviatile was placed in the genus Chromobacterium (11) as a matter of convenience pending the study of further 
strains, as the guanine-plus-cystosine content of the species was too low for formal inclusion. The DNA-ribosomal ribonucleic acid hybridization studies of Moss and Bryant (9) further supported the recognition of a new genus for this species. The present work confirms both the homogeneity of the $C$. fluviatile taxon and the need for it to be recognized as a genus separate from Chromobacterium; accordingly, the new genus lodobacter is proposed to accommodate this species, and a description follows.

Iodobacter gen. nov. Iodobacter gen. nov. (from Gr. adj. ioeides violet-colored; M. L. masc. $\mathrm{n}$. bacter, the equivalent of Gr. neut. n. bacterion, a small rod; M.L. masc, $n$. Iodobacter, a violet-colored, small rod): gram-negative, straight, round-ended rods 0.7 by 3.0 to $3.5 \mu \mathrm{m}$, occurring singly, in pairs, sometimes in chains, and occasionally as long filaments. Motile with a single polar flagellum and one or more lateral flagella. Grow on ordinary peptone media. On low-nutrient media such as 1 NA, colonies usually differ from those of Chromobacterium and Janthinobacterium species by being very thin, with rough surfaces and irregular edges, and spreading to $1 \mathrm{~cm}$ or more in diameter; they are of butyrous consistency and are easily emulsified in water. Occasional strains may spread only poorly and may produce slightly gelatinous colonies. All strains produce nonspreading colonies on rich media. Most strains produce the violet pigment violacein, and this shows most intensely in the centers of spreading colonies. Growth in ${ }^{1} \mathrm{NB}$ is moderate after $24 \mathrm{~h}$ at $25^{\circ} \mathrm{C}$, with uniform turbidity and a violet ring at the surface but no pellicle; strains forming long filaments may appear to gel in broths. Chemoorganotrophs; facultative anaerobes which attack carbohydrates fermentatively without gas production. Grow at 4 to about $30^{\circ} \mathrm{C}$, with optimum growth around $25^{\circ} \mathrm{C}$. Iodobacter species differ from Chromobacterium species by inability to grow at $37^{\circ} \mathrm{C}$ and from Janthinobacterium species by anaerobic growth and fermentative attack of carbohydrates. Other characters useful for separating these genera are shown in Table 1.

lodobacter fluviatile comb. nov. Iodobacter fluviatile comb. nov. has all the characters defining the genus. In addition, it has the following properties: positive for growth in $1 \% \mathrm{NaCl}$; positive for oxidase; production of acid from fructose, glucose, maltose, mannose, trehalose, and $\mathrm{N}$-acetylglucosamine; utilization of malate as the sole carbon source; and hydrolysis of gelatin. Negative for growth in $4 \% \mathrm{NaCl}$ and at $\mathrm{pH} 3$; production of acid from arabinose, cellobiose, galactose, glycogen, inositol, inulin, lactose, mannitol, melezitose, raffinose, sorbitol, starch, sucrose, and xylose; utilization of lactate, proprionate, or tartrate as the sole carbon source; hydrolysis of aesculin, arginine, and starch; production of hydrogen cyanide; reduction of nitrite; production of gas from nitrate. Sensitive to the following antibiotics: chloramphenicol, chlortetracycline, furazolidone, kanamycin, nalidixic acid, nitrofurantoin, oxytetracycline and tetracycline; slightly sensitive to neomycin, streptomycin, and sulfafurazole; resistant to ampicillin, cephaloridine, colistin, penicillin $\mathrm{G}$, and vibriostatic agent $0 / 129$. Variable properties (with proportion of strains giving positive results shown in parentheses) are: spreading colonies ( $89 \%$ ), gelatinous colonies $(4 \%)$, and zoning of pigment $(6 \%)$ on ${ }^{1} \mathrm{NA}$; violacein production (83\%); formation of chains of cells $(34 \%)$ and filaments (15\%); growth at $30^{\circ} \mathrm{C}(83 \%)$, in $2 \% \mathrm{NaCl}(9 \%)$, and at $\mathrm{pH} 4(19 \%)$ and $\mathrm{pH} 9(98 \%)$; growth on minimal medium $(96 \%)$ and $4 \mathrm{NA}(45 \%)$; production of acid from gluconate $(96 \%)$ and glycerol $(13 \%)$; utilization of acetate $(89 \%)$, citrate $(85 \%)$, fumarate $(89 \%)$, glycerate $(60 \%)$, pyruvate $(79 \%)$, and succinate $(94 \%)$; hydrolysis of casein $(90 \%)$; hemolysis (92\%); egg yolk reaction (13\%); nitrate reduction $(98 \%)$. The guanine-plus-cytosine contents of the DNA from three strains ranged from 50 to $52 \mathrm{~mol} \%$ as determined by melting temperature (11).

Isolated from running fresh water in England and Scotland, and reported (19) from Antarctic lakes. Strains of this species are infrequently isolated, and the selective medium of Ryall and Moss (12) is recommended, with subsequent cultivation on $-\mathrm{NA}$ or in ${ }_{-1} \mathrm{NB}$.

Description of the type strain. The type strain is NCTC 11159 (strain C009 in the present study) and has the characters of the species. With respect to variable characters, tests are positive for production of spreading colonies and violacein; growth at $30^{\circ} \mathrm{C}$, on minimal medium, and at $\mathrm{pH} 5$; production of acid from gluconate; utilization of acetate, citrate, fumarate, glycerate, pyruvate, or succinate as the sole carbon source; hydrolysis of casein; hemolysis; and nitrate reduction. Tests were negative for production of gelatinous colonies; zoning of pigment; formation of chains of cells; filamentous forms; growth in $2 \% \mathrm{NaCl}$, at $\mathrm{pH} 4$, and on $4 \mathrm{NA}$; production of acid from glycerol; and egg yolk reaction.

\section{ACKNOWLEDGMENTS}

The donations of strains by D. Cullen, M. O. Moss, and D. D. Wynn-Williams and the isolation of several unpigmented strains by Margaret Ritchie are gratefully acknowledged. It is with special pleasure that I thank Wilma Dodd and her colleagues for expert technical services and Roger Evans for his enthusiastic and unstinting assistance with computing.

This work was supported by a Glasgow College of Technology Small Grant for Research.

\section{LITERATURE CITED}

1. Cowan, S. T., and K. J. Steel. 1974. Manual for the identification of medical bacteria, 2nd ed. Cambridge University Press, Cambridge.

2. Cruickshank, R., J. P. Duguid, B. P. Marmion, and R. H. A. Swain. 1975. Medical microbiology, 12th ed., vol. 2. Churchill Livingstone, Edinburgh.

3. De Ley, J. 1978. The correlation between rRNA similarities and bacterial ecology, p. 18-20. In M. W. Loutit and J. A. R. Miles (ed.), Microbial ecology. Springer-Verlag, Berlin.

4. De Ley, J., P. Segers, and M. Gillis. 1978. Intra- and intergeneric similarities of Chromobacterium and Janthinobacterium ribosomal ribonucleic acid cistrons. Int. J. Syst. Bacteriol. 28: 154-168.

5. Gauthier, M. J. 1976. Morphological, physiological, and biochemical characteristics of some violet-pigmented bacteria isolated from seawater. Can. J. Microbiol. 22:138-149.

6. Gordon, R. E., and J. M. Mihm. 1957. A comparative study of some strains received as Nocardiae. J. Bacteriol. 73:15-27.

7. Keeble, J. R., and T. Cross. 1977. An improved medium for the enumeration of Chromobacterium from soil and water. J. Appl. Bacteriol. 43:325-327.

8. Mayfield, C. J., and W. E. Inniss. 1977. A rapid method for staining bacterial flagella. Can. J. Microbiol. 23:1311-1313.

9. Moss, M. O., and T. N. Bryant. 1982. DNA:rRNA hybridization studies of Chromobacterium fluviatile. J. Gen. Microbiol. 128: 829-834.

10. Moss, M. O., and C. Ryall. 1980. The genus Chromobacterium, p. 1355-1364. In M. P. Starr, H. Stolp, H. G. Truper, A. Balows, and H. G. Schlegel (ed.), The prokaryotes, vol. 2. Springer-Verlag, Berlin.

11. Moss, M. O., C. Ryall, and N. A. Logan. 1978. The classification and characterization of chromobacteria from a lowland river. $\mathrm{J}$. Gen. Microbiol. 105:11-21.

12. Ryall, C., and M. O. Moss. 1975. Selective media for the enumeration of Chromobacterium spp. in soil and water. J. Appl. Bacteriol. 38:53-59.

13. Sivendra, R., H. S. Lo, and K. T. Lim. 1975. Identification of 
Chromobacterium violaceum: pigmented and non-pigmented strains. J. Gen. Microbiol. 90:21-31.

14. Sneath, P. H. A. 1974. Genus Chromobacterium Bergonzini 1881,153 , p. $354-357$. In R. E. Buchanan and N. E. Gibbons (ed.), Bergey's manual of determinative bacteriology, 8th ed. The Williams \& Wilkins Co., Baltimore.

15. Sneath, P. H. A. 1984. Genus Janthinobacterium De Ley, Segers and Gillis $1978,164^{\mathrm{AL}}$, p. 376-377. In N. R. Krieg and J. G. Holt (ed.), Bergey's manual of systematic bacteriology, vol. 1. The Williams \& Wilkins Co., Baltimore.

16. Sneath, P. H. A. 1984. Genus Chromobacterium Bergonzini $1881,153^{\mathrm{AL}}$, p. $580-582$. In N. R. Krieg and J. G. Holt (ed.),
Bergey's manual of systematic bacteriology, vol. 1. The Williams \& Wilkins Co., Baltimore.

17. Sneath, P. H. A., and R. Johnson. 1972. The influence on numerical taxonomic similarities of errors in microbiological tests. J. Gen. Microbiol. 72:377-392.

18. Ward, N. R., R. L. Wolfe, C. A. Justice, and B. H. Olson. 1986. The identification of Gram-negative nonfermentative bacteria from water: problems and alternative approaches to identification. Adv. Appl. Microbiol. 31:293-365.

19. Wynn-Williams, D. D. 1983. Distribution and characteristics of Chromobacterium in the maritime and sub-Antarctic. Polar Biol. 2:101-108. 